(RESEARCH ARTICLE)

\title{
Hepatoprotective activities of aqueous extract of oyster mushroom (Pleurotus ostreatus) against lead-induced hepatotoxicity in albino Wistar rats (Rattus norvegicus)
}

\author{
Zitte Leelee Famii * and Unegbu Christian Ebuka \\ Department of Animal and Environmental Biology, Faculty of Science, University of Port Harcourt, Nigeria.
}

Publication history: Received on 13 September 2019; revised on 20 October 2019; accepted on 22 October 2019

Article DOI: https://doi.org/10.30574/wjarr.2019.3.3.0062

\begin{abstract}
The present study was undertaken to investigate the hepatoprotective activities of aqueous extract of Pleurotus ostreatus (oyster mushroom) against lead-induced hepatotoxicity in Rattus norvegicus (albino Wistar rat). The different groups of the animals (groups 2, 3, 4, 5 and 6) were administered a single dose of lead after groups 3, 4, 5 and 6 have been pre-treated with aqueous extract of Pleurotus ostreatus at concentrations of $50 \mathrm{mg} / \mathrm{kg}, 250 \mathrm{mg} / \mathrm{kg}$, $500 \mathrm{mg} / \mathrm{kg}$ and $1000 \mathrm{mg} / \mathrm{kg}$ daily, respectively for 21 days. Hepatoprotective effects were studied by the liver marker enzymes concentration assay [Alanine Aminotransferase (ALT) and Aspartate aminotransferase (AST)]. Hepatotoxicity- induced rats (group 2(control II)) showed increased level of ALT and AST $(26.25 \pm 1.49$ vs $21.57 \pm 1.32$ and $54.75 \pm 5.13$ vs $35.5 \pm 1.66 \mathrm{U} / \mathrm{L}, \mathrm{P}<0.05$ ) in serum when compared to group 1 (control I). On the other hand, the rats pre-treated with aqueous extract of Pleurotus ostreatus showed hepatoprotective effects by maintaining the levels of ALT (group 3: 14.00 \pm 1.58 , group 4: $15.50 \pm 2.18$, group 5: $14.75 \pm 2.50$ and group 6: $13.75 \pm 1.18 \mathrm{U} / \mathrm{L}$ ) and AST (group 3: $37.75 \pm 5.20$, group 4: $44.25 \pm 2.87$, group 5: $51.25 \pm 1.89$ and group 6: $44.00 \pm 1.96 \mathrm{U} / \mathrm{L}$,) in the serum around the normal levels. These were observed to be significantly lower than group 2 . This result reveals that aqueous extract of Pleurotus ostreatus demonstrated some degree of hepatoprotection against lead induced hepatocellular injury. Hence, it is recommended that Pleurotus ostreatus be included as one of the functional food with hepatoprotective qualities.
\end{abstract}

Keywords: Pleurotus ostreatus; Hepatoprotective; Rattus norvegicus; Aspartate aminotransferase (AST); Alanine Aminotransferase (ALT)

\section{Introduction}

Lead is a naturally occurring toxic metal found in the Earth's crust. Its widespread use has resulted in extensive environmental contamination and significant public health problems in many parts of the world [1]. There have also been reports of Lead as a common environmental pollutant with its associated environmental effects as a result of its uses in industries in the production of lead-acid batteries, lead wire or pipes, and metal recycling [2,3] . Human beings are also being exposed to Lead through contact with lead in air, household dust, soil, water, and commercial products [4]. Eating of food grown in contaminated soil can present lead hazard [5].

Researches have shown that lead are majorly stored in the blood, soft tissues, and bones, and the half-life of lead in these tissues are in weeks, months and years respectively. However, when lead is exposed to organs like liver and kidney, it poses a threat to the physiological wellbeing of that individual [6].

Over the years, medicinal and herbal therapies have been used to alleviate liver damages. The growing interest in the use of herbal therapy due to their little or no side effects have fueled many researchers to discover many herbal

\footnotetext{
${ }^{*}$ Corresponding author

E-mail address: leelee.zitte@uniport.edu.ng
} 
products. Several studies have demonstrated the protective effects of herbs against experimentally induced liver injury. Specifically, the edible mushroom is known to have some therapeutic properties such as antioxidant [7, 8], antitumor/anticancer [9], antimicrobial, immunomodulatory [10], anti-inflammatory [11], antiatherogenic and hypoglycemic actions [8] in different trials.

Injury to the liver, whether acute or chronic, eventually results in an increase in serum concentrations of the common liver enzymes aminotransferases: aspartate aminotransferase (AST) and alanine aminotransferase (ALT) [12].

The two methods commonly used to remove heavy metals from the body include chelation and supportive measures. Chelation is a chemical process that has applications in many areas, including medical treatment, environmental site rehabilitation, water purification and many others. Several chelating compounds have been used to manage lead toxicity but none is so suitable in reducing lead burden in chronic lead exposure [13].

Moreover, these chelating agents, in turn, are potentially toxic [14] and often fail to remove lead burden from all body tissues, according to research report on chelating agents and lead toxicity management. In order to address this problem, natural therapies to promote chelation, detoxification and protection are gaining popularity especially due to their minimal or no side effects. Medicinal properties of plants have also been investigated in the light of recent scientific developments throughout the world, as a result of their potent pharmacological activities, low toxicity and economic viability [15].

Choudhury [16] reported that $P$. ostreatus extract has significant therapeutic effects on blood pressure and glycemic status of hypertensive diabetic male volunteers. Lentinus edodes extract prevented severity of liver damage caused by paracetamol as evidenced by the low level of bilirubin in the serum [17].

\section{Material and methods}

This study was conducted in the Department of Animal and Environmental Biology, Animal House, Choba Campus, University of Port Harcourt, Choba, Rivers State, Nigeria. Dry P. ostreatus was purchased from the mushroom farm in Rivers State University, Port Harcourt, Rivers State, Nigeria and pulverized with electric blender. The powdered mushroom ( $650 \mathrm{~g}$ ) was maserated in three litres of water then boiled for 30 minutes. It was later filtered through no1 watman filter paper. The supernatant was evaporated to dryness to have the aqueous extract.

A total of twenty four (24) healthy, adult Wistar strain of albino rats of both sexes weighing 150-200 g were used for this study. They were equally distributed into six (6) groups of four animals each. The animals were acclimatized for two weeks and fed with poultry growers mash and water ad libitum. Animals were maintained under standard condition of 12- hour's light/ dark cycle and at an ambient temperature of $23 \pm 2{ }^{\circ} \mathrm{C}$, with $65 \pm 5 \%$ humidity.

Groups 3, 4, 5 and 6 were pre-treated with crude aqueous extract of Pleurotus ostreatus of concentrations $50 \mathrm{mg} / \mathrm{kg}$, $250 \mathrm{mg} / \mathrm{kg} .500 \mathrm{mg} / \mathrm{kg}$ and $1000 \mathrm{mg} / \mathrm{kg}$ respectively for 21 days. Thereafter, groups 2, 3, 4, 5 and 6 were treated with $200 \mathrm{mg} / \mathrm{kg}$ single dose of lead each. Within 24 hours the animals were anesthetized and blood collected from the retro-orbital venous for blood analysis.

Data were analyzed using ANOVA in SPSS statistical software with the result expressed as mean \pm standard error (SE).

\section{Results}

The administration of lead in rats resulted in a significant hepatic damage as observed from the average mean elevated levels of serum ALT and AST (Fig 1) as shown in group 2(control II) below. Group 1(control I) showed a normal level of serum ALT $(21.75 \pm 1.32)$ and AST $(35.5 \pm 1.66)$.

The results obtained showed that in the serum levels of ALT, mean $( \pm$ SEM) of group 1 and group 2 were $21.75 \pm 1.32$ and $26.25 \pm 1.49$ respectively (Fig. 1). No statistically significant mean difference of the two groups was seen (p > 0.05). However, of the pre-treated groups; group 3 (50 mg/kg), group 4 (250 mg/kg), group 5 (500 mg/kg) and group $6(1000 \mathrm{mg} / \mathrm{kg})$ were $14.00 \pm 1.58,15.50 \pm 2.18,14.75 \pm 2.50$ and $13.75 \pm 1.18$ respectively (Fig. 1$)$ were all statistically different $(\mathrm{p}<0.05)$ from the group 2 , but were not significantly different $(\mathrm{p}>0.05)$ from one another. 
Simultaneously, the serum levels of AST of group 1 and group 2 were $35.50 \pm 1.66$ and $54.75 \pm 5.13$ respectively. With a statistically significant mean difference $(\mathrm{p}<0.05)$ between the two groups. Also, the levels in the pre-treated groups; group 3 (50 mg/kg), group 4 (250 mg/kg), group 5 (500 mg/kg) and group 6 (1000 mg/kg) were $37.75 \pm 5.20,44.25$ $\pm 2.87,51.25 \pm 1.89$ and $44.00 \pm 1.96$ respectively. These were not significantly different $(p>0.05)$ from one another, but they were significantly different $(\mathrm{p}<0.05)$ from group 2(Fig).

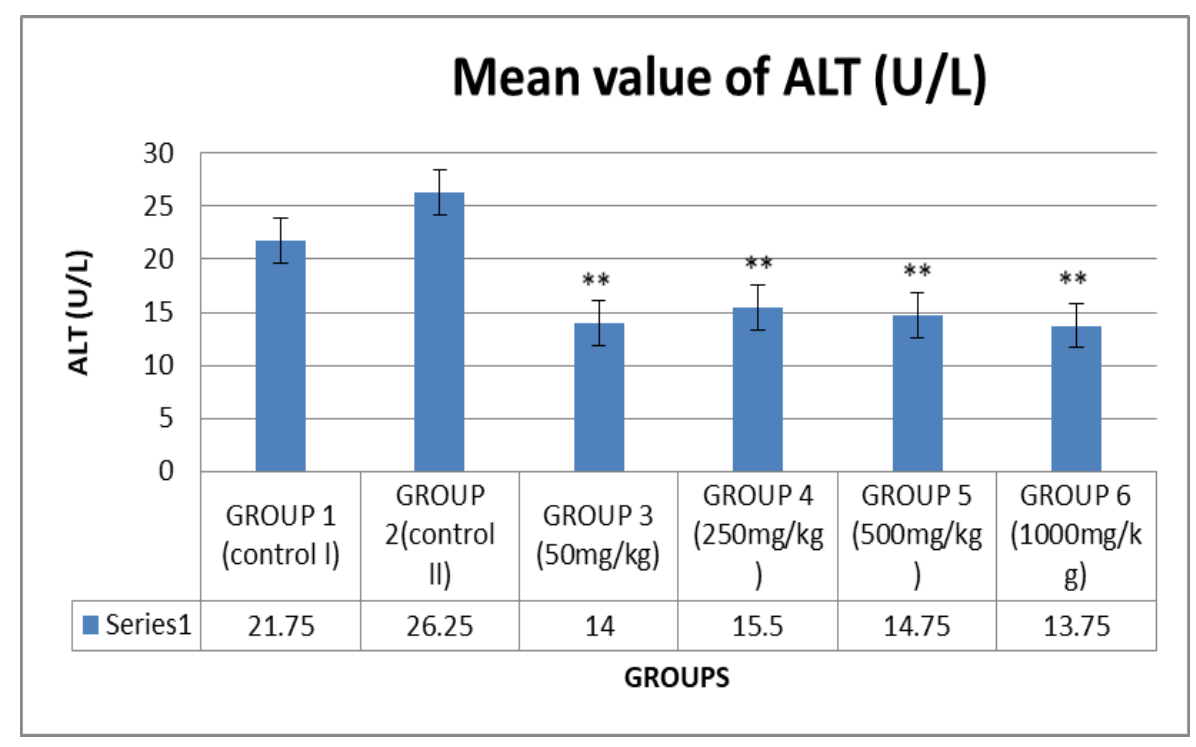

Figure 1 Levels of serum ALT in lead induced hepatotoxic rats and aqueous extracts from $P$. ostreatus pre-treated rats. ** Significant when compared to group 2(control II)

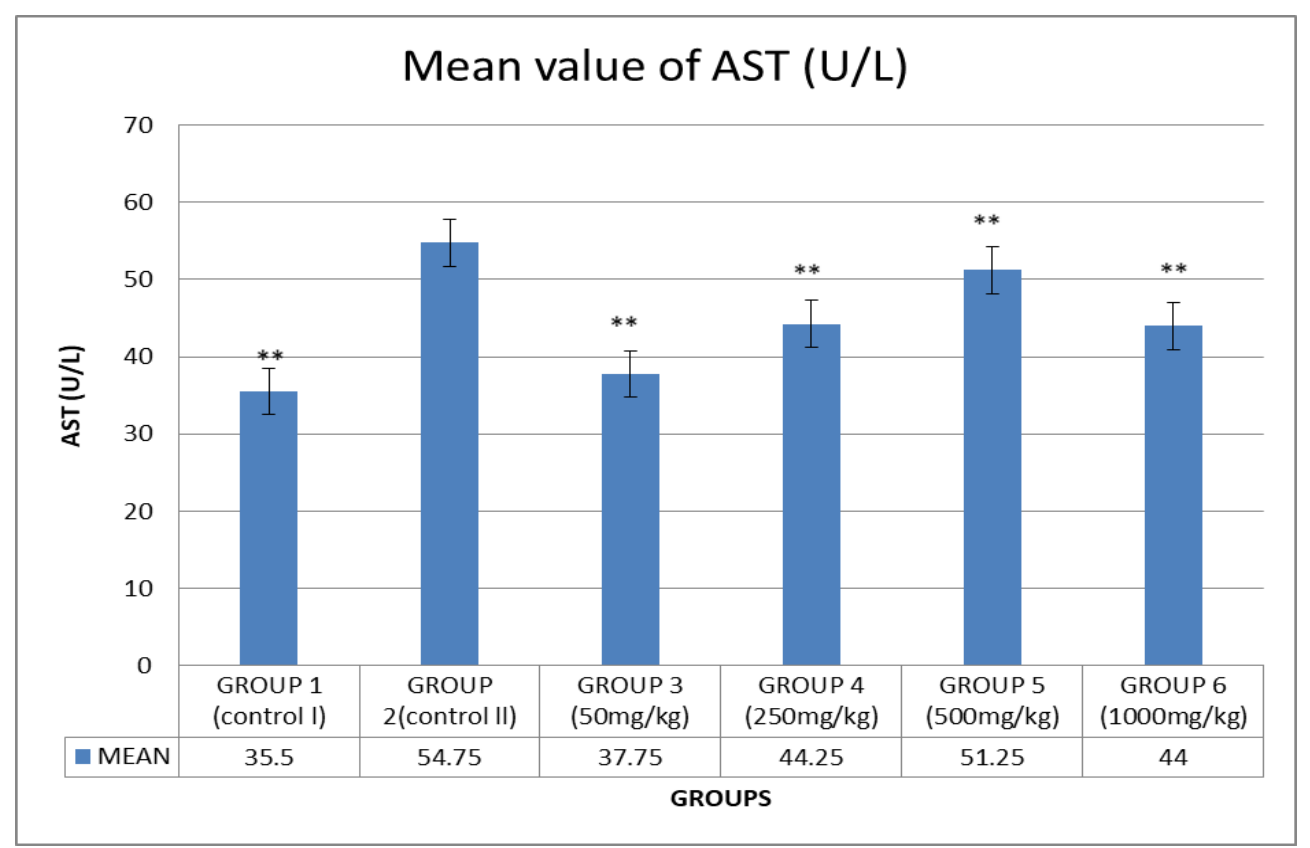

Figure 2 Levels of serum AST in lead induced hepatotoxic rats and aqueous extracts from P. ostreatus pre-treated rats. ** Significant when compared to group 2(control II)

\section{Discussion}

The experimental intoxication induced by lead is widely used for modeling liver injury in rats. Hepatotoxicity is connected with severe impairment of cell protective mechanisms. Pleurotus ostreatus extracts, on the other hand, have been reported to possess potent antioxidant, antihypercholesterolemic, immunomodulatory and anticancer properties [18]. In similar way, potential hepatoprotective effects have also been reported. 
In the present study, the results demonstrated that the administration of high dose of lead in group 2 (control II) significantly increased serum levels of acute liver damage indicators. However, direct evidence of lead hepatotoxicity was noted in the occurrence of dramatic elevations in the levels of serum ALT and AST when compared to group 1 (control I) which is the normal ALT and AST levels, and the mushroom pretreated groups( groups $3,4,5$,and 6) Thus, is in agreement with previous reports. [19].

In accordance with the results, pre-treatment with oyster mushroom aqueous extract significantly provide protection against hepatic injury due to lead. When the serum ALT and AST activities were compared with the controls (I \& II). Data obtained revealed that the concentration levels of serum ALT and AST were significantly $(\mathrm{P}<0.05)$ lower in groups pre-treated with the mushroom extract when compared with group 2 . It therefore demonstrated that mushroom extract has a potent hepatoprotective effects against lead hepatotoxicity [20] .The observed hepatoprotective effect might be as a result of the amelioration of the underlying mechanisms by which lead causes cellular damage, with subsequent suppression of the leakage of these enzymes into the blood.

However, the serum level ALT varied randomly between the groups. The data revealed that the pre-treated groups was significantly different from the controls (II) the mean values showing significant reduction of the serum ALT. It was also observed from the data that the level of the serum ALT in the pretreated groups were below the value for the normal range. This was in agreement with the report of [21]. The serum levels of AST also varied randomly between the groups with significant difference when compared to group 2(control II) to confirm its hepatoprotective activity. Data from the mean values also showed a significant difference when compared to both group 1 and group 2 .

\section{Conclusion}

Finally, it can be concluded that aqueous extract of Pleurotus ostreatus is hepatoprotective against lead induced hepatotoxicity in Wister albino rats. Serum ALT and AST showed differences in the enzymes concentration as a result of lead-induced hepatotoxicity, which was correspondingly alleviated by the hepatoprotective activities of Pleurotus ostreatus. However, the hepatoprotective potential was not dose dependent in the pretreated groups. It is therefore recommended that researches on the efficacy of different doses of mushroom extracts and at different durations be carried out so as to arrive at a definite effective dose for hepatoprotective treatment.

\section{Compliance with ethical standards}

\section{Acknowledgments}

We have to use this medium to acknowledge the administration of the Department of Animal and Environmental Biology Faculty of Science, University of Port Harcourt, for the research oriented program and the enabling environment for scholastic research in the Department.

\section{Disclosure of conflict of interest}

There is no conflict of interest amongst the authors of this manuscript.

\section{Statement of ethical approval}

University of Port Harcourt Ethical Committee granted approval to carry out this research work with a mild discomfort on the animal subjects.

\section{References}

[1] Bellinger D. (2008). Very low lead exposures and children's neurodevelopment current opinion in pediat. J. Ind. Med., 172-177.

[2] Ragan P and Turner T. (2009). Working to prevent lead poisoning in chidern: getting the lead out. JAAPA, 22(7), 40-50.

[3] Manay N, Cousillas AZ, Alvarez C and Heller T. (2008). lead contamination in Uruguay: the La Teja. Reviews of enviromental contamination and toxicology., 195, 93-115.

[4] Rossi E. (2008). Low level enviromental lead exposure-a continual challange. The Clinical Biochemist. Reviews/Australian Association Of Clinical Biochemist., 29(2), 63-70. 
[5] Yu MH. (2005). Enviromental metals and metalliods. Enviromental Toxicology:Biological and Health Effects of Pollutants, 188.

[6] Karri SK, Saper RB and Kales SN. (2008). Lead encephalopathy due to traditional medicines. Current drug safety, 3(1), 54-9.

[7] Puttaraju NG, Venkateshaiah SU, Dharmesh SM, Urs SMN and Somasundaram R. (2006). Antioxidant activity of indigenous mushrooms. J. Agric. Food Chem., 54, 9764-9772.

[8] Ferreira ICFR, Barros L and Abreu RMV. (2009). Antioxidants in wild mushrooms. Curr. Med. Chem., 16, 15431560.

[9] Moradali MF, Mostafavi H, Ghods S and Hedjaroude GA. (2007). Immunomodulating and anticancer in the realm of macromycetes fungi (macrofungi). Intern. Immunopharmacol., 7, 701-724.

[10] Borchers A, Keen CL and Gershwin ME. (2004). Mushrooms, Tumors, and Immunity: An update. Soc. Exp. Biol. Med., 229, 393-406.

[11] Moro C, Palacios I, Lozano M, DÁrrigo M, Guillamón E and Villares A. (2012). Anti-inflammatory activity of methanolic extracts from edible mushrooms in LPS activated RAW 264.7 macrophages. Food Chem., 130, 350355.

[12] Sheth SG, Flamm SL, Gordon FD and Gordon V. (2003). AST/ALT ratio predicts cirrhosis in patients with chronic hepatitis C virus infection. Am J Gastro- enterol, 93, 44-48.

[13] Lawrence W. (2015) Chelation therapy.The center for development, 3, 142 -145.

[14] Gilman AG, Rall TW and Nies AS. (2008). Goodman and Gilman's. The pharmacological basis of therapeutics. New York: Pregamon.

[15] Janmeda P, Sharma V, Singh L, Paliwal R, Sharma S and Yadav S. (2011). Chemopreventive Effect of hydroethanoic extract of Euphobia nerifolia leaves against DENA- induced hepatic and renal carcinogenesis in mice. Asian Pacific. J. Cancer Prev., 12, 677-683.

[16] Choudhury MBK, Rahman T, Kakon AJ, Hoque N, Akhtaruzzaman M and Begum MM. (2013). Effect of Pleurotus ostreatus on blood pressure and glycemic status of hypertensive diabetic male volunteers. Bangladesh. J. Med. Biochem., 6(1), 5-10.

[17] Jayakumar T, Ramesh E and Geraldine P.(2006). Antioxidant activity of the oyster mushroom, Pleurotus ostreatus , on CCl4-induced liver injury in rats . Food Chem. Toxicol., 44, 1989-1996.

[18] Jones S and Janardhanan KK. (2000). Antioxidant and antitumor activity of Ganoderma lucidum (Cart. Fr.) P.Karst.-Reishi (Aphyllophoromycetidae) from South India. Int. J. Med. Mushroom, 2, 195-200.

[19] Lockitch G. (1993). Perpective on lead toxicity. Cline. Biochem., 26, 371-381.

[20] Rana T, Kumar Bera A, Das S, Bhattacharya D, Pan D and Bandyopadhyay S. (2012). Pleurotus florida lectin normalizes duration dependent hepatic oxidative stress responses caused by arsenic in rat. Exp. Toxicol. Pathol., 64, 665-371.

[21] Kim RW, Flamm SL, Bisceglie AM and Bodenheimer HC. (2008). Serum activity of alanine aminotransferase (ALT) as an indicator of health and disease. Hepatology, 47, 1363-1370.

\section{How to cite this article}

Zitte LF and Unegbu CE. (2019). Hepatoprotective activity of aqueous extract of oyster mushroom (Pleurotus ostreatus) against lead-induced hepatotoxicity in albino Wister rats (Rattus norvegicus). World Journal of Advanced Research and Reviews, 3(3), 33-37. 